\title{
Hot fluids or rock in eclogite metamorphism?
}

\author{
Arising from: A. Camacho, J. K. W. Lee, B. J. Hensen \& J. Braun Nature 435, 1191-1196 (2005)
}

The mechanisms by which mafic rocks become converted to denser eclogite in the lower crust and mantle are fundamental to our understanding of subduction, mountain building and the long-term geochemical evolution of Earth. Based on larger-than-expected gradients in argon isotopes, Camacho et al. ${ }^{1}$ propose a new explanation - co-seismic injection of hot $\left(700^{\circ} \mathrm{C}\right)$ aqueous fluids into much colder $\left(400^{\circ} \mathrm{C}\right)$ crust - for the localized nature of eclogite metamorphism during Caledonian crustal thickening, as recorded in the rocks of Holsnøy in the Bergen arcs, western Norway. We have studied these unusual rocks ${ }^{2-4}$, which were thoroughly dehydrated under granulite facies conditions during a Neoproterozoic event (about 945 million years (945 Myr) ago); we also concluded that fracture-hosted fluids were essential as catalysts and components in the conversion to eclogite about $425 \mathrm{Myr}$ ago ${ }^{5}$. However, we are sceptical of the assertion by Camacho et al. that eclogite temperatures were reached only in the vicinity of fluid-filled fractures. Determining whether these rocks were strong enough to fracture at depths of $50 \mathrm{~km}$ because they were cold or because they were very dry is crucial to understanding the mechanics of the lower crust in mountain belts, including, for example, the causes of seismicity in the Indian plate beneath the modern Himalayas ${ }^{6}$.

The interpretation by Camacho et al. of their argon-isotope data is inconsistent with reasonable magnitudes of heat and fluid advection, as well as with structural field relations in these rocks, for two reasons. First, immense quantities of fluid - equal at a minimum to the mass of eclogitized rock - would have been required to heat the rocks to $300^{\circ} \mathrm{C}$ above the ambient temperature. Moreover, the source of any such superheated fluids is not obvious for the Holsnøy complex. There is no evidence of magmatism at the time of the eclogite metamorphism and, because the rocks resided somewhere within the overthickened Caledonian crust, any fluids derived from a subducting slab would have had to travel long distances $(20 \mathrm{~km}$, assuming a geothermal gradient of $\left.15^{\circ} \mathrm{C} \mathrm{km}^{-1}\right)$ without losing their heat in order to trigger edogite-grade reactions in cold rocks.

Second, Camacho et al. suggest that the observed occurrence of edogite in 10-100-mwide shear zones could be explained by multiple seismically triggered episodes of hot fluid injection into the same sites. However, consideration of structural relationships make this scenario implausible. Although most of the eclogites occur as shear zones, cross-cutting relationships show that these shear zones were secondary results of, rather than the primary conduits for, fluid infiltration. Brittle tensile and shear fractures, as well as pseudotachylyte (glassy rock generated by frictional melting during seismic slip), are seen exclusively in the almost anhydrous granulite facies rocks, whereas only eclogitized areas show evidence of pervasive ductile strains that overprint the granulite-facies fabric ${ }^{5}$.

These ubiquitous structural relationships indicate that the dry granulite was much stronger than the slightly rehydrated (phengite- and zoisite-bearing) eclogites, which accommodated very large ductile shear strains following their metamorphic conversion. Although it is surprising to see evidence of frictional sliding behaviour at such depths and temperatures, the virtual absence of hydrous phases in the gabbroic to anorthositic granulites can account for their unusual rheological properties at high temperatures ${ }^{78}$.

Once formed, the eclogites on Holsnøy were apparently too weak to fracture, seismically or otherwise, and they responded to far-field stresses instead by ductile deformation making repeated, rapid infiltration of large volumes of fluid into the same sites unlikely. The resultant shear zones may have been loci of slow, diffuse fluid flow, but under such conditions the fluids would have steadily lost their heat to the surrounding rocks if the ambient temperature had been only $400^{\circ} \mathrm{C}$. Hence, the scenario proposed by Camacho et al. ${ }^{1}$ cannot readily account for the broadest belts of eclogite, such as the Hundskjeften shear zone (shown in Fig. 1 of ref. 1), which is as much as $500 \mathrm{~m}$ wide. We suspect that the profound decrease in strength upon conversion to edogite caused the metamorphic process to be self-limiting and that it resulted in the observed 'patchiness' of the eclogitized areas ${ }^{5}$.

We find that the model proposed by Camacho et al. is at odds not only with plausible geophysical constraints but also with some of the principal characteristics of this remarkable rock complex, which provides a rare glimpse of how different geological processes may be when rocks are exceptionally dry.

M. G. Bjørnerud ${ }^{\star}$, H. Austrheim $\dagger$

*Geology Department, Lawrence University,

Appleton, Wisconsin 54912, USA

e-mait: bjornerm@lawrence.edu

†Physics of Geological Processes Project,

Department of Earth Sciences, PO 1047,

University of Oslo, 0316 Oslo, Norway

1. Camacha, A, Lee, L.K.W. Hensen, B I. \& Braun, J. Nature 435, 1191-1196 (2005)

2. Austrheim, H. \& Griffin W. Chem. Geal. 50, 267-281(1985).

3. lamtveit, B, Austrheim, H. \& Malthe-Sorensen, A.Nature 408, $75-78(2000)$.

4. Austrheim, H. \&Boundy, T.Science 265, 82-83 (1994).

5. Bjornerud, M, A ustrheim, H.\& Lund, M.J.Geophys Res. 107,2252-2269(2002)

6. lackson, LA, Austrheim, $\mathrm{H}$, McKenzie, D. \& Priestly, K. Gealogy 32, 625-628 (2004).

7. Mackwell, S, Zimmerman, M. \& Kohlstedt, D.J. Geophys. Res. 103,975-984 (1998).

8. Rubey, D. in Deformation Processesin Mineuls Ceramics and Rodss (eds Barber, D.\& Meredith, P.) 262-295 (Chapman and Hall, New York, 1990).

doi:10.1038/nature04714

\section{GEOPHYSICS}

\section{Camacho et al. reply}

\section{Replying to: M.G. Bjørnerud \& H.Austrheim Nature 440, doi:10.1038/nature04714 (2006)}

Bjørnerud and Austrheim ${ }^{1}$ interpret the geological evidence in the rocks of Holsnøy at Lindås nappe, Norway, to be inconsistent with our cold-crust model ${ }^{2}$, but do not question our new argon isotopic data, on which we base the thermal history of the terrain. A critical flaw underlying their arguments $\mathrm{s}^{1,3}$ is the implicit assumption that element diffusion does not occur in dry environments, although there is clear evidence to the contrary $y^{2,4,5}$. Counter to earlier claims $\mathrm{s}^{3,6}$ of element and isotope immobility in dry rocks, we have demonstrated the existence of diffusion profiles in phlogopite associated with the uptake of argon during the Caledonian in 'unreacted' protolith of the
Lindås nappe. Diffusion has taken place in these dry rocks and cannot be ignored.

Addressing their specific objections to our model in turn, we consider first the transport of hot fluids through the crust. Our contention is not that the whole terrain was heated by $300{ }^{\circ} \mathrm{C}$, but rather that regional ambient temperatures were not significantly affected by localized advection of hot fluids. Regarding the source of fluids, it is widely accepted that ample volumes can be provided from dehydration of the subducted rocks and there is nothing to prevent these fluids travelling long distances.

Second, regarding the temporal relationship of fluid access, recrystallization and 